\title{
Musik Pengiring dalam Upacara Ngalaksa Masyarakat Rancakalong Sumedang
}

\author{
ELA YULAELIAH* \\ Jurusan Etnomusikologi, Fakultas Seni Pertunjukan, Institut Seni Indonesia Yogyakarta
}

\begin{abstract}
Accompanying Music in Ngalaksa Ceremony at Rancakalong Community of Sumedang. This research is intended to study the important role of music accompanying Ngalaksa ceremony held by the society of Rancakalong, Sumedang District, West Java. Although this ceremony is recently oriented to be a tourist destination, but its original function as a thanksgiving ceremony and original form of ceremony is still kept in accordance with the custom inherited from generation. One thing that can not be separated from Ngalaksa ceremony is the Tarawangsa music performance and Kecapi played for seven days and seven nights. By using Etnomusicological approach, it can be known that the music within Ngalaksa ceremony plays a very important role for generating religious situation and for accompanying spontaneous dances.
\end{abstract}

Key words: Ngalaksa ceremony, tarawangsa, kecapi.

\section{Pendahuluan}

Upacara Ngalaksa merupakan sebuah kegiatan yang dilakukan secara turun temurun satu tahun sekali oleh masyarakat desa Rancakalong kabupaten Sumedang Jawa Barat. Kegiatan tersebut merupakan atraksi budaya masyarakat Sunda agraris sebagai pengungkap rasa syukur dan permohonan berkah dari Tuhan Yang Maha Esa. Permohonan berkah dilimpahkan melalui alam pertanian yang mereka miliki. Masyarakat Rancakalong percaya bahwa alam dapat memberi kehidupan dan kekuatan dalam kehidupannya (R.H. Hasan Mustapa, 2002: 86).Ungkapan rasa syukur tersebut diwujudkan dengan mengadakan upacara Ngalaksa.

Ngalaksa adalah upacara membuat makanan dari hasil panen masyarakat setempat dengan tujuan agar masyarakat dapat mengekspresikan rasa terima kasih atas segala berkah Tuhan, dengan diberi kesuburan dalam mengolah tanah pertanian. Dengan kata lain, upacara Ngalaksa merupakan upacara yang berkaitan dengan ritual kesuburan dan sebagai sarana penghormatan kepada Dewi Sri sebagai Dewi Pohaci atau Ibu Padi dengan diiringi musik tarawangsa dan kacapi selama tujuh hari tujuh malam.
Secara etimologis Ngalaksa berasal dari kata laksa yang diberi awalan 'nga' sehingga menjadi kata kerja yaitu ngalaksa membuat bubur dari tepung beras. Laksa adalah sejenis makanan dengan bahan dasar tepung beras yang diolah sedemikian rupa hingga menjadi suatu jenis makanan seperti lontong yang dibungkus dengan daun congkok. Laksa tersebut direbus dengan daun combrang sebanyak ribuan buah (Sukarma, 2006).

Upacara Ngalaksa dilakukan secara bergilir di antara lima kampung yang ada di kecamatan Rancakalong. Tempat upacara dipusatkan di rumah seorang tokoh masyarakat (sesepuh) yang biasa disebut rurukan (untuk menyebut nama kampung yang melaksanakan upacara Ngalaksa). Kelima rurukan tersebut adalah, rurukan Rancakalong, rurukan Cijere, rurukan Legok Picung, rurukan Cibunar dan rurukan Pasir Biru. Akan tetapi, setelah adanya ketetapan pemerintah daerah kabupaten Sumedang yang mengangkat upacara Ngalaksa menjadi agenda wisata daerah, tanpa merusak makna dan tujuannya sejak tahun 1990 upacara Ngalaksa dipusatkan di satu tempat (desa wisata Rancakalong) dengan memakai patokan kalender nasional yang selalu jatuh pada bulan Juli. Penetapan tanggal biasanya hasil kesepakatan

\footnotetext{
*Alamat korespondensi: Jl. Parangtritis km. 6,5 Yogyakarta 55001. Tlp. 0274-375380, HP: 08122748396e-mail: ela_etno@ yahoo.com
} 
antara unsur pemda dengan sesepuh masyarakat yang akan mengadakan upacara Ngalaksa. Hari pelaksanaan upacara dihitung dan ditentukan berdasarkan hari pasaran. Puncak acara, yakni hari ke- 7, harus jatuh pada hari pasaran Kliwon.

Pelaksanaan upacara Ngalaksa yang dilaksanakan selama tujuh hari tujuh malam, selalu diiringi oleh instrumen musik tarawangsa yangjuga disebut jentreng/ngek-ngek dan kacapi. Ensambel ini dimainkan selama upacara berlangsung tiada henti kecuali pada saat tiba waktu sembahyang/ sholat dan ketika adanya pergantian pemain. Selama musik dimainkan, selama itulah aktivitas membuat laksa dilakukan yang sesekali diselingi dengan menari dengan gerakan spontan. Hal ini sangat menarik dan menimbulkan satu pertanyaan, bagaimana peran musik pengiring dalam upacara tersebut.

Ada beberapa orang yang telah melakukan penelitian dengan objek upacara Ngalaksa yaitu, Mardiana (1986) meneliti instrumen pengiring upacara Ngalaksa dari sisi teknik memainkan tarawangsa, Sukhaenah (2000) meneliti tentang profil desa wisata Rancakalong, dan Nurlaelaningsih (2005) meneliti dari segi tari dalam upacara Ngalaksa. Berbeda dengan penelitian sebelumnya, fokus penelitian ini secara khusus mengamati peran musik pengiring dalam upacara Ngalaksa.

\section{Upacara Ngalaksa}

Ada dua hal yang saling terkait dalam pembahasan ini, yaitu musik dan upacara yang keduanya merupakan satu kesatuan yang tidak dapat dipisahkan. Oleh sebab itu, deskripsi upacara Ngalaksa, diperlukan untuk mengetahui peranan musiknya.

Upacara Ngalaksa adalah salah satu kegiatan ritualyang dilakukan oleh masyarakat Rancakalong sebagai ungkapan rasa syukur atas limpahan berkah panen yang meruah dan diadakan sekali dalam satu tahun. Waktu pelaksanaannya telah disepakati oleh Pemda dan masyarakat yakni berdasarkan tanggalan Komariah. Pelaksanaannya lebih ditata dengan banyak melibatkan unsurunsur kesenian Sunda. Dapat dikatakan bahwa upacara Ngalaksa merupakan sebuah upacara syukuran hasil pertanian yang sudah ditata sedemikian rupa hingga menjadi sebuah seni budaya (Oting, 2006).
Prosesi pertama upacara Ngalaksa adalah menyimpan padi ke lumbung untuk diinepkeun (diinapkan) dan telah diberi sesaji yang terdiri dari pakaian, makanan (jajan pasar), peralatan bertani, bunga, bubur merah, bubur putih, air kopi, dan sebagainya. Prosesi ini dilakukan pada siang hari setelah acara pembukaan. Adegan ini mempunyai simbol bahwa Dewi Sri akan menetap di tempatnya (lumbung). Padi yang telah diinapkan di lumbung tersebut akan menjadi benih istimewa yang akan dijadikan calon benih untuk masa tanam selanjutnya.

Kegiatan berikut yang dilakukan pada malam harinya, adalah pembuatan laksa dengan cara merendam gabah yang telah dibersihkan selama tiga hari tiga malam hingga muncul tunas seperti kecambah. Gabah yang sudah direndam selama tiga hari, dijadikan sebagai bahan laksa dan kecambahnya disisihkan dan diyakini bisa dijadikan obat untuk kesehatan maupun obat untuk pembasmi hama. Oleh sebab itu, kecambah tersebut akan menjadi rebutan masyarakat yang mengikuti upacara.

Gabah yang sudah terkelupas dan menjadi beras pada hari keempat, kemudian ditumbuk bersama oleh ibu-ibu selama dua hari hingga menjadi tepung. Peserta upacara laki-laki mempersiapkan tungku dan kuali besar untuk membuat laksa. Tepung beras hasil tumbukan akhirnya digodok pada kuali besar dengan bumbu parutan kelapa, garam, sedikit irisan daun combrang dan air yang diproses seperti membuat bubur namun dibuat agak keras hingga bisa dibungkus dengan daun congkok (seperti daun kelapa) dan direbus kembali sampai matang. Proses pembungkusan dan perebusan laksa memakan waktu satu sampai dua hari yaitu pada hari keenam. Laksa dibungkus (seperti lontong) sebanyak mungkin bahkan sampai ribuan bungkus. Masyarakat memercayai bahwa jumlah yang didapat pada saat itu memberi gambaran akan keberhasilan panen berikutnya. Bila pada saat itu dapat menghasilkan bungkus laksa yang lebih banyak dari tahun kemarin maka mereka berkeyakinan berkah melalui panen yang akan datang pun akan lebih berlimpah.

Setelah tepung beras menjadi bubur (laksa), pemimpin upacara yang disebut saehu (sesepuh) akan mengambil sebagian kecil laksa untuk digencet (ditekan pada sebuah papan) sehingga terpotongpotong. Prosesi ini sebagai simbol menghilangkan 
bala atau membuang yang kotor seperti halnya umat Islam yang melaksanakan khitanan pada anak laki-laki. Oleh sebab itu proses ini disebut sebagai proses khitanan yang dilakukan pada puncak acara atau hari ketujuh.

Selama prosesi upacara yang berlangsung tujuh hari tujuh malam suara tarawangsa yang disebut juga jentreng/ngek-ngek dan kacapi, terus dibunyikan dengan cara digesek dan dipetik untuk membawakan lagu-lagu instrumental (tanpa syair) secara bergantian. Pada puncak acara hari ketujuh, digelar tari-tarian yang dibawakan oleh peserta upacara baik yang laki-laki maupun perempuan secara bergantian. Tarian yang dibawakan secara spontan dengan diiringi tarawangsa, dilakukan di depan pemain tarawangsa sambil mengelilingi sesaji yang lengkap. Puncak acara itu dilakukan pembagian ribuan bungkus laksa pada seluruh peserta upacara, sisanya di bawa oleh rurukan untuk dibawa ke kampungnya masing-masing.

\section{Musik Pengiring dalam Upacara Ngalaksa}

Instrumen musik sebagai pengiring upacara Ngalaksa, selalu menggunakan instrumen musik tarawangsa yang berpasangan dengan instrumen kacapi.Dalamhalinitarawangsamenjadiinstrumen pokok sebagai pembawa melodi, sedangkan kacapi merupakan instrumen pendamping sebagai pembawa irama dan pembawa arkuh lagu (pola lagu). Masyarakat Rancakalong menyebut ensambel tarawangsa dan kacapi pada upacara Ngalaksa disebut juga jentreng/ngek-ngek. Istilah atau sebutan ini diambil dari suara tarawangsa, yaitu bila digesek akan mengeluarkan suara 'ngekngek' dan ada satu dari ketiga senar tarawangsa yang cara memainkannya dipetik yang menghasilkan bunyi ngajentreng (Atik Soepandi,1977:22). Kacapi sebagai pasangan dari tarawangsa, adalah jenis kacapi yang mirip kacapi Baduy dengan jumlah senar 7 buah. Masyarakat Rancakalong meyakini bahwa tarawangsa merupakan instrumen tinggalan karuhun masyarakat Rancakalong yang memang fungsinya dari dahulu secara turun-temurun sebagai pengiring upacara padi (Suarma, 2006).

\section{Tarawangsa}

Tarawangsa adalah instrumen semacam rebab yang cara bunyikannya dengan cara digesek. Permainan tarawangsa biasa dimainkan secara mandiri maupun secara ensambel dengan instrumen lain. Seperti halnya tarawangsa yang dipakai dalam upacara Ngalaksa selalu berpasangan dengan kacapi.Tarawangsa adalah instrumen gesek tertua yang ada di Jawa Barat dan merupakan pengembangan instrumen celempung (Jonathan Rigg, 1862: 503).

Apabila ditinjau dari klasifikasi dari Mahillon - Sach - Von HornBostel yang mengklasifikasikan alat musik berdasarkan bahan yang digunakan hingga menghasilkan suara yang berbeda-beda yakni, idiophone, aerophone, membranophone, chordophone, dan electrophone (Pono Banoe, 1984: 13), instrumen tarawangsa termasuk ke dalam klasifikasi chordophone, yaitu instrumen berdawai dengan teknik bermain digesek. Ada beberapa daerah di Jawa Barat yang masih memakai tarawangsa sebagai penunjang aktivitas masyarakat petani, baik untuk upacara maupun untuk hiburan, antara lain di Baduy disebut rendo, di Rancakalong disebut tarawangsa atau ngekngek, di Garut disebut tarawangsa, di Cibalong Tasikmalaya juga disebut tarawangsa, dan sebagainya.

\section{Kacapi}

Kacapi tertua di Sunda adalah kacapi yang berasal dari Baduy dengan sebutan kacapi Baduy. Bagi masyarakat Baduy, kacapi dianggap sebagai barang keramat yang tidak boleh dimainkan sembarangan. Mereka berkeyakinan bahwa kacapi adalah penjelmaan dewa yang bersuara bagus atau disebut Batara endah sora (Van Zanten, 1989:96).

Bentuk kacapi Baduy, ada kemiripan dengan kacapi rincik yang bentuknya seperti perahu dengan ukuran lebih kecil dari kacapi indung/ kacapi parahu dan mempunyai jumlah senar 7 sampai 12 senar. Bentuk kacapi seperti kacapi baduy, tidak hanya terdapat di Baduy saja, akan tetapi terdapat juga di beberapa daerah di Sunda yang fungsinya sama yaitu untuk kepentingan upacara padi. Salah satu daerah yang memakai kacapi untuk kepentingan upacara padi adalah di Rancakalong (Enip Soekanda, 1996: 5). Instrumen kacapi sebagai pasangan tarawangsa di dalam upacara Ngalaksa merupakan instrumen yang termasuk dalam kelompok chordhofone, yaitu alat musik berdawai dengan teknik memainkannya adalah dipetik. 


\section{Peranan Musik dalam Upacara Ngalaksa}

Peranan musik dalam upacara Ngalaksa, akan ditinjau melalui unsur-unsur pendukung musiknya seperti sistem notasi, laras yang digunakan, lagulagu yang dimainkan serta bentuk dan struktur lagu. Permainan tarawangsa dan kacapi, memakai sistem notasi daminatila dengan simbol angka mulai dari 1 sampai dengan 5 . Notasi daminatila terdiri dari 5 nada pokok (1 23345 ) dan 2 nada sisipan (3-, 5+). Nada sisipan ini dipakai khusus untuk laras pelog. Deretan notasi daminatila 7 nada dalam 1 gembyang/oktaf adalah 1 (da), 2 (mi), 3- (ni), 3 (na), 4 (ti), 5 (la), 5+ (leu), 1 (da rendah).

Laras adalah urutan nada-nada yang sudah tersusun dan sudah ditentukan jarak dan tinggi rendah nadanya. Dalam budaya musik pentatonik, khususnya karawitan Sunda, ada 4 buah laras, yaitu: laras salendro, laras madenda, laras degung dan laras pelog. Laras yang digunakan pada tarawangsa dalam upacara Ngalaksa biasanya adalah laras pelog tujuh nada termasuk dengan nada sisipan atau nada tengahan. Digunakannya laras pelog tujuh nada, disebabkan karena tarawangsa tugasnya membawakan melodi lagu dengan penggunaan jumlah nada yang lebih banyak yaitu 7 nada (1 2 3-3 455 5+). Berbeda dengan permainan kacapi yang selalu memakai laras pelog 5 nada tanpa memakai nada sisipan (3- dan 5+). Hal ini disebabkan karena kacapi bertugas sebagai pembawa irama dan ritme yang dapat dimainkan hanya dengan laras pelog 5 nada (1 $\left.2 \begin{array}{llll}1 & 2 & 4 & 4\end{array}\right)$.

Alasan dipakainya laras pelog dalam mengiringi upacara Ngalaksa adalah, karena sudah dilakukan secara turun temurun oleh masyarakat Rancakalong (Oting, 2006). Penggunaan laras pelog yang berkarakter tenang (Atik Soepandi, 1976: 35), dalam upacara Ngalaksa sesuai dengan kebutuhan sebuah upacara yang membutuhkan suasana tenang dan, khidmat.

Seperti telah diutarakan bahwa, permainan musik yang dibawakan oleh tarawangsa dan kacapi adalah jenis lagu instrumental/tanpa syair yang terbagi menjadi tiga bagian (pembukaan, isi dan penutupan) yang di dalamnya menyajikan lagulagu pokok, sedangkan lagu bebas dimainkan di luar urutan upacara inti .

Lagu-lagu pokok dalam upacara Ngalaksa adalah lagu yang tersusun sesuai dengan urutan upacara yang seolah membentuk alur cerita, yaitu dibuka dengan lagu pamapag, lagu panimang, lagu pangapungan dan sebagai penutup adalah lagu keupat eundang.

Pada bagian pembukaan atau saat dimulainya upacara, selalu dimainkan lagu dengan judul pamapag (penjemputan). Lagu ini digambarkan sebagai lagu penjemputan para leluhur/Dewi Sri agar dapat hadir di tengah-tengah peserta upacara. Dilanjutkan dengan lagu panimang yang dimainkan sebagai pembangkit suasana khidmat, namun pada bagian ini banyak peserta upacara yang secara spontan menggerakan badannyal menari mengikuti lagu yang dibawakan tarawangsa dan kacapi.

Pada bagian isi, dilakukan pada hari yang sama setelah pembukaan. Lagu pokok yang selalu dimainkan adalah lagu yang berjudul panimang (menimang padi). Mereka meyakini pada bagian ini para karubun atau Dewi Sri telah hadir di antara mereka dan ikut menimang padi sambil menari. Tarian yang mereka bawakan dapat dikatakan sebuah ekspresi kekhusukan yang diiringi musik sederhana dengan cara menggerakkan badan/ menari secara spontan. Lagu berikutnya adalah lagu berjudul pangapungan, (terbang kembali ke alam gaib) yang menggambarkan suasana mengantarkan kembali para leluhur/Dewi Sri ke alam gaib. Bagian pembukaan dan isi dilaksanakan pada hari yang sama atau satu hari.

Hariberikutnya adalah proses pembuatan laksa, yang dilakukan selama 6 hari, musik tarawangsa dan kacapi terus dimainkan untuk mengiringi taritarian spontan baik yang dilakukan di atas balebale, maupun untuk mengiringi tarian spontan dari para pembuat laksa. Untuk mengiringi tarian pada bagian ini disajikan lagu-lagu bebas seperti, lagu Badud, Angin-angin, Saur dan sebagainya.

Pada bagian penutupan yang dilaksanakan pada hari ke 7 atau puncak acara, akan ditutup dengan dimainkannya lagu pokok berjudul keupat eundang. Penutupan biasanya dilakukan setelah masuk waktu azan asyar. Pada saat itulah beriburibu laksa pun siap dinikmati secara bersamasama dan dibagi-bagikan kepada seluruh hadirin yang hadir pada saat itu.

Berikut ini adalah contoh lagu pokok dan lagu bebas, dengan teknik penulisan notasi pokok atau pola lagu yang dibawakan oleh tarawangsa dan 
kacapi. Dalam hal ini, tarawangsa membawakan melodi lagu dan kacapi sebagai pembawa ritme dan irama mengikuti nada kenongan dan jatuhnya nada goongan.

a. Lagu Keupat Eundang (lagu pokok)

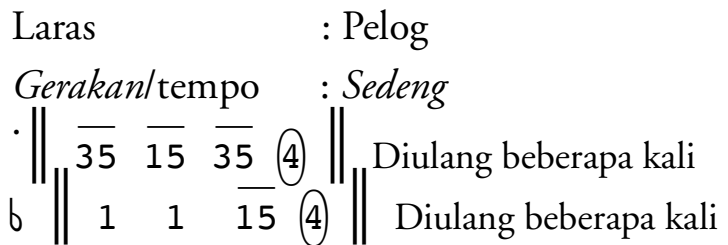

Lagu tersebut diulang-ulang menurut keinginan pemain.

Tabuhan kacapi:
$\left\|\begin{array}{lllllll}1 & 1 & -1 & 1 & 1 & 1 & 1 \\ \hline & 5 & \cdot & 5 & 5 & 5 & 5\end{array}\right\|$

Keterangan:

$\mathrm{n}$ : Jatuhnya nada kenongan

$\mathrm{g}$ : jatuhnya nada goongan.

Pola lagu di atas dimainkan secara berulangulang mengikuti melodi lagu yang dibawakan tarawangsa.

b. Lagu Badud (lagu bebas)

Melodi lagu yang dibawakan tarawangsa

Laras : Pelog

Gerakan/tempo: Sedeng

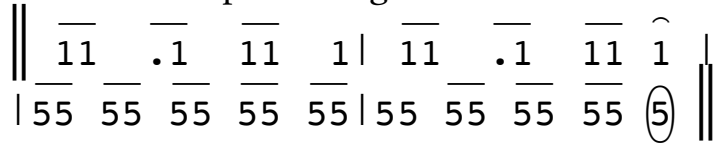

Lagu yang dibawakan kacapi:

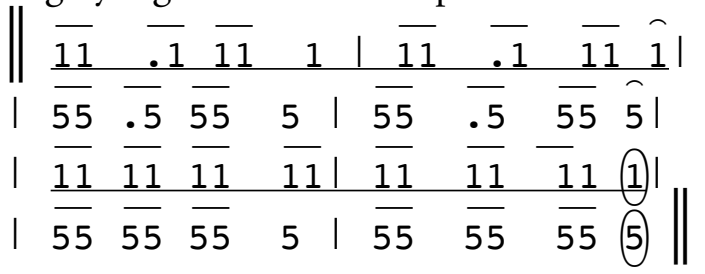

Ada dua fungsi lagu yang dibawakan tarawangsa dengan iringan kacapi yaitu, sebagai iringan tari baik dalam acara pokok maupun sebagai selingan di sela-sela pembuatan laksa. Berikutnya adalah sebagai pembangkit suasana agar tercipta suasana religius dan khidmat selama upacara inti berlangsung. Dengan kata lain bahwa, peran musik dalam upacara Ngalaksa tidak dapat dipisahkan antara musik sebagai pembangkit suasana maupun musik sebagai iringan tari. Hal ini disebabkan karena musik dimainkan dalam waktu yang bersamaan untuk kepentingan dua peran yang berbeda. Dengan kata lain, lagu dimainkan dengan tujuan membangkitkan suasana, namun peserta upacara saat itu juga dengan spontan akan menari mengikuti irama dan lagu yang dibawakan oleh tarawangsa dan kacapi.

Bahasan tentang bentuk dan struktur musik dari permainan tarawangsa dan kacapi tidak akan terlepas dari fungsi musik tersebut di dalam upacara Ngalaksa. Fungsi musik dalam upacara Ngalaksa adalah untuk membangun suasana khidmat pada saat pembukaan dan pada saat puncak acara/ penutupan yang juga sekaligus sebagai pengiring tarian spontan.

Lagu pokok yang dibawakan tarawangsa merupakan lagu pendek yang dimainkan secara berulang-ulang. Pengulangan lagu juga terdapat pada iringan kacapi yang memainkan pola ritme dengan mengikuti jatuhnya kenongan dan goongan dari lagu yang dibawakan tarawangsa. Pada bagian lagu pokok, instrumen tarawangsa pada umumnya memainkan melodi lagu, sedangkan kacapi berperan sebagai pemberi tekanan nada yang jatuh pada setiap akhir birama. Nada akhir dalam satu birama dari melodi tarawangsa, akan jatuh pada nada yang sama dengan nada kacapi. Terlihat adanya permainan harmoni dalam permainan kacapi pada beberapa lagu yaitu harmoni antara nada 1 (da) dan 5 (la) yang dipetik secara bersamasama. Jarak nada penghasil harmoni antara 1 - 5 dalam karawitan Sunda disebut interval salah gumun (Atik Soepandi, 1976: 27). Pola permainan instrumen seperti ini (motif ritme yang sederhana, ajeg, dan diulang-ulang), melahirkan nuansa sakral/magis, sedangkan gesekan tarawangsa dengan melodi lagunya, melahirkan suasana yang menyayat tapi khidmat.

Selaras dengan fungsi awal kesenian tradisional Sunda pada umumnya adalah berkaitan dengan upacara padi, baik yang dilaksanakan sebelum maupun sesudah panen (Ela Yulaeliah, 2003:165), maka tarawangsa dan kacapi dengan nuansa musikal yang dihasilkan (sakral atau magis) dan bentuk lagunya yang khas sangat pas/cocok dimainkan dalam upacara Ngalaksa. Secara umum bentuk lagu yang dimainkan dalam upacara Ngalaksa adalah bentuk lagu pendek, yakni hanya terdiri dua sampai enam baris melodi yang dimainkan secara berulang-ulang. Bentuk lagu yang pendek seperti ini merupakan hal yang wajar karena musik ini pada umumnya berfungsi sebagai 
pembentuk atau pembangkit suasana khidmat. Begitu pula dengan bentuk lagu bebas yang biasa dipakai untuk mengiringi tarian spontan, bentuk dan strukturnya pun sama dengan lagu pokok. Hal ini sejalan dengan pendapat I Wayan Senen, bahwa sebagai salah satu ciri musik ritual pengiring upacara pada umumnya adalah musik atau lagu instrumental maupun vokal yang berbentuk sederhana (I Wayan Senen, 1997: 18).

\section{Penutup}

Pelaksanaan upacara Ngalaksa pada mulanya selalu diadakan tiga tahun sekali setelah masyarakat melakukan panen raya yang biasanya jatuh pada bulan Maulud. Pada perkembangannya upacara Ngalaksa diadakan satu tahun sekali dengan berpegang pada tanggalan Komariah yakni atas kesepakatan saehu (pemimpin upacara) dengan pemda yang biasanya jatuh pada bulan Juli. Di samping adanya perubahan waktu, tempat pelaksanaannya pun berubah. Tempat upacara mulanya dilaksanakan di kampung/rurukan secara bergantian, sekarang tempatnya dipusatkan di sebuah tempat yang dibuat pemda dengan nama desa wisata Rancakalong dan menjadi aset Wisata Pemda.

Instrumen tarawangsa dan kacapi sebagai musik pengiring dalam upacara Ngalaksa sangat berperan penting, yang selama upacara berlangsung instrumen tersebut selalu dimainkan. Dengan kata lain upacara Ngalaksa tidak dapat dipisahkan dengan musik pengiringnya. Berdasarkan analisis musik dengan upacara Ngalaksa, ditinjau dari aspek laras, lagu yang dimainkan, bentuk dan struktur lagunya, menunjukkan hubungan yang sangat erat dengan upacara tersebut. Penggunaan laras pelog, nama lagu yang sesuai dengan konteks upacara, bentuk dan struktur lagu yang sederhana, pendek dan berulang-ulang, sangat mendukung suasana religius upacara.

Musik pengiring dalam upacara Ngalaksa secara global berperan sebagai pembangkit suasana dan sebagai pengiring tari. Musik sebagai pembangkit suasana masuk ke dalam prosesi/inti upacara dengan membawakan lagu-lagu pokok, sedangkan musik sebagai iringan tari pada acara selingan, selalu membawakan lagu-lagu bebas. Namun demikian, keduanya tidak dapat dipisahkan, karena dalam kenyataannya setiap musik dibunyikan baik yang termasuk ke dalam upacara inti maupun pada acara selingan selama pembuatan laksa, semua yang hadir akan mengegerakkan badan dan menari sambil duduk di tempat maupun berdiri secara spontan.

\section{Ucapan Terimakasih}

Ucapan terimakasih disampaikan pada Disbudpar Kabupaten Sumedang Jawa Barat dan bapak Mama Sukarma yang telah memberikan tempat pemondokan selama penulis mengadakan penelitian.

\section{Kepustakaan}

Banoe, Pono. 1984. Pengantar Pengetahuan Alat Musik. Jakarta: C.V. Baru.

Hasan Mustapa, RH. 2002. Adat Istiadat Sunda. terj. Maryati Sastrawijaya. Bandung: Alumni.

Merriam, Alan P. 1964. The Antrhopology of Music. Northwestern: University Press.

Rigg, Jonathan. 1862. A Dictionary of the Sunda Language of Java. Batavia: Lange and Co.

Senen, I Wayan. 1997. "Aspek Ritual Musik Nusantara". Pidato Ilmiah Pada Dies Natalis XII Institut Seni Indonesia Yogyakarta.

Soepandi, Atik dan Enoch Atmadibrata. 1977. Khasanah Kesenian Daerah Jawa Barat. Bandung: Pelita Masa.

Sukanda, Enip. 1996. Kacapi Sunda. Bandung: Direktorat Jendral Kebudayaan.

Yulaeliah, Ela. 2003. "Seni Pantun Sunda: Antara Ritual dan Hiburan," dalam Resital, Jurnal Ilmiah Seni Pertunjukan Edisi IV/02, Desember 2003.

Zanten, Wim Van. 1989. Sundanesse Music in the Cianjuran Style. USA: Dordrecth Holan, Providence.

\section{Narasumber}

Mama Sukarma (70 tahun), tokoh Ngalaksa desa Rancakalong.

Oting (54 tahun), saehu rurukan Cibunar. 